\title{
Eco-friendly Antimicrobial Finishing of Cotton Fabric using Plant Extracts
}

\author{
Jyoti V. Vastrad* and Shameembanu A. Byadgi \\ All India Coordinated Research Project - Home Science (Clothing and Textiles), MARS, \\ University of Agricultural Sciences, Dharwad, Karnataka, India
}

*Corresponding author

\begin{abstract}
A B S T R A C T
\section{Keywords}

Antibacterial activity,

Escherichia coli,

Eucalyptus globulus,

Staphylococcus

aureus, Tinospora

cordifolia, Tridax

procumbens, Total

phenolic content

Article Info

Accepted:

04 January 2018

Available Online:

10 February 2018

The comprehensive focus on plant based extract in textile coating as antimicrobial textile finish has gained significant momentum and is an emerging technology in the production of medical cloths. The present study was undertaken to assess the antibacterial activity of cotton fabric treated with E. globulus, T. cordifolia and T. procumbens leaf extracts. Extraction of phytochemicals was carried out by different solvents viz., ethanol, methanol and distilled water. Total phenolic content results revealed that TPC of E. globulus and T. procumbens was high in ethanol $(302.67$ and $42.20 \mathrm{mg} / \mathrm{g})$ extract whereas in case of $T$. cordifolia, high TPC was found to be in distilled water extract $(465.82 \mathrm{mg} / \mathrm{g})$. Bioassay results revealed that crude ethanol extract of all the plant sources exhibited good antibacterial activity against $S$. aureus and E. coli compared to 5 and $10 \%$ extract concentrations. Further, irrespective of the sources, the fabrics treated with $10 \%$ ethanol extract exhibited positive antibacterial activity against both the test organisms. This study thus explored the antimicrobial functionality of cotton fabrics coated with plant extract as value added textile product. Hence it can be concluded that the leaf extracts of E. globulus, $T$. cordifolia and $T$. procumbens can be efficiently used as antimicrobial agent for the preparation of antimicrobial textile finish particularly for medical cloths.
\end{abstract}

\section{Introduction}

Clothing considered to be the second skin, is responsible for a healthy and contagious free living. Functionality of clothing depends on attributes such as wrinkle resistance, soil release, water repellency, flame retardancy and resistance to microbial invasion. Besides, textiles serve as excellent substrate for bacterial growth and microbial proliferation under appropriate moisture, nutrients and temperature conditions (Hooda et al., 2013). Therefore, the activity of fabric to resist disease transmission is being considered to be an important and inevitable parameter for garments which come in direct contact with human body.

The rapid growth in technical textiles and their end-uses has generated many opportunities for the application of innovative finishes. Any operation (chemical or mechanical) for improving the appearance or usefulness of fabric is known as finishing. It can change a fabric's aesthetic and/or physical properties, as well as its texture and surface characteristics 
(Khurshid et al., 2015). Novel finishes of added value for apparel fabrics are also greatly appreciated by a more discerning and demanding consumer market. Among various chemical finishes, antimicrobial finish has got great importance due to its relation with healthcare and medical textiles. Antimicrobial textiles with improved functionality find a variety of applications such as health and hygiene products, specially the garments worn close to the skin and several medical applications, such as infection control and barrier material.

Antimicrobial agents inhibit the growth or kill microbes to control their negative effect e.g. odour, staining and deterioration. Microbes are the tiniest of creatures, which cannot be seen by the naked eye. They consist of a variety of micro-organisms like bacteria, fungi, algae and viruses etc. There are various antimicrobial agents used as textile finishes that can be classified as synthetic and natural agents (Khurshid et al., 2015). Applications of natural antimicrobial agents have gained considerable attention in the field of medical and health care textiles due to properties such as being environment friendly, skin friendly, safe and non-toxic as compared to synthetic antimicrobial agents.

Plants possess a wide variety of secondary metabolites which have been found in vitro to have antimicrobial properties. Extracts from different parts of diverse species of plants like roots, leaves, flowers and seeds exhibit antimicrobial properties (Sathianarayanan et al., 2011). Eucalyptus globulus is a member of Myrtaceae family, it is well known as medicinal plants because of their biological and pharmacological properties. The essential oils from E. globulus are having great demand in the market, because of their anesthetic, antiseptic, astringent, disinfectant properties. They are also used as a folk remedy for arthritis, asthma, burns, diabetes, leprosy, skin rashes (Vastrad et al., 2016). Tinospora cordifolia, known as Amrutballi is, a climber plant which belongs to the family Menispermaceae. Extracts of this plant has been shown to possess many therapeutic properties including general tonic, antiinflammatory, anti-arthritic, anti-malarial, aphrodisiac, anti-allergic, anti-diabetic, antihepatotoxic and antipyretic (Vastrad et al., 2015). Although, the active components responsible for therapeutic effects of $T$. cordifolia are not well defined; phenylpropanoid glycosides such as cordifolioside A, cordifolioside B and syringin, have been reported to be main immunomodulatory active components (Cho et al., 2001).

Tridax procumbens Linn, commonly known as coat buttons or tridax daisy, is widely distributed weed found everywhere in India, America, Tropical Africa, Asia, and Australia. All plant parts have noble pharmacological activities like hepatoprotective effect, immunomodulating property, promising wound healing activity, antidiabetic, hypotensive effect, antimicrobial, insect repellent activity, anti-inflammatory and antioxidant, bronchial catarrh, dysentery, diarrhoea (Kale and Deshmukh, 2014).

The use of natural products for antimicrobial finishing of textiles has opened up new avenues in the field of technical textiles. Although there are many natural sources rich in antimicrobial agents, the study on their use in textiles is very limited and not documented. The major challenges in application of natural sources for textile application are that majority of the sources are complex mixtures of several compounds and also the composition varies in different species of the same plant (Gupta and Laha, 2007). However, because of their ecofriendly nature and non-toxic properties, they are still considered as novel means for niche applications such as medical and health care 
textiles. Hence the present study was designed with the objectives to characterize the plant extracts for antimicrobial activity, standardize a protocol for application of antimicrobial finish and to assess the performance of treated fabrics.

\section{Materials and Methods}

\section{Plant sources}

Leaves of eucalyptus (Eucalyptus globulus), tinospora (Tinospora cordifolia) and tridax (Tridax procumbens) were collected in the premises of University of Agricultural Sciences, Dharwad. The leaves were shade dried and ground in laboratory mixer/blender. The substrate was passed through sieve to separate the unwanted residue to obtain fine powder.

\section{Preparation of extract}

A known quantity of leaf powder was mixed in $70 \%$ ethanol, $70 \%$ methanol and distilled water and incubated for 24 hours at room temperature. The extract was centrifuged at room temperature for $10,000 \mathrm{rpm}$ and supernatant was separated. The extract obtained was filtered using Whatman filter paper and measured. Extracts were stored at $8^{0} \mathrm{C}$ for further analysis within 7 days (Vastrad et al., 2015).

\section{Total Phenolic Content (TPC)}

TPC in the extracts was determined by FolinCiocalteu assay method (Singleton and Rossi, 1965) with little modification using gallic acid as the reference standard. Briefly, all the solvent extracts were diluted to appropriate volumes and were mixed with $2 \mathrm{ml}$ of $10 \%$ $\mathrm{Na}_{2} \mathrm{CO}_{3}$ solution. Incubated at room temperature for $3 \mathrm{~min}, 100 \mu \mathrm{l}$ of FolinCiocalteu reagent was added to the mixture. The resulting solution was incubated for 90 min at room temperature under dark, the absorbance was measured at $765 \mathrm{~nm}$ using the UV-Vis Spectrophotometer. The TPC was expressed as gallic acid equivalent (GAE) in milligrams per gram of fresh leaf (Figure 1). Based on the TPC, the solvent which yielded maximum phenolic content was further selected for bioassay experiment.

\section{Bioassay of plant extracts}

Bioassay was carried out to assess the antibacterial activity of the plant extracts by Well Diffusion Method. The bacterial species viz., Staphylococcus aureus (ATCC 6538) and Escherichia coli (ATCC 8739) were used for the study.

Nutrient media and nutrient broth was prepared separately in distilled water and autoclaved at $120{ }^{\circ} \mathrm{C}$ for 15 minutes at a pressure of $15 \mathrm{lb}$. A loopful of bacterial $(S$. aureus and E. coli) cultures was mixed separately in the nutrient broth and kept under shaking condition for 24 hours. The bacterial inoculum was uniformly spread on sterile Petri plates and allowed to solidify. Later, four wells were created using a cork borer $(10 \mathrm{~mm}$ diameter). The ethyl alcohol extract $(100 \%$, $10 \% \& 5 \%$ ) of selected plant sources were added to each of the respective 3 wells, one well of 70 per cent ethyl alcohol. The Petri plates were incubated for 18-24 hrs and observed for bacterial growth. Zone of inhibition of the bacterial growth was measured in $\mathrm{mm}$.

\section{Application of antimicrobial finish}

Ethyl alcohol extracts (5\% and 10\%) of plant sources were applied on pre-treated cotton fabric by pad-dry-cure method. The fabric was immersed in the plant extract containing 6\% citric acid (binding agent) for ten minutes and passed through pneumatic padding mangle at a speed of $3 \mathrm{~m} / \mathrm{min}$ with a pressure of $1 \mathrm{~kg} / \mathrm{cm}^{2}$ 
to remove excess solution. Later, the fabric was air dried and cured for 3 minutes at 140 ${ }^{\circ} \mathrm{C}$.

\section{Antibacterial activity of treated fabrics}

The treated fabrics were then tested for antibacterial activity as per AATCC 147 test standard. Sterilized nutrient agar was poured in petri plates and allowed to gel firmly. $1 \pm$ $0.1 \mathrm{ml}$ of 24 hours old broth culture was transferred into $9 \pm 0.1 \mathrm{ml}$ sterile distilled water and mixed properly.

One loopful of diluted inoculum was loaded and five lines of $60 \mathrm{~mm}$ length spacing $10 \mathrm{~mm}$ apart were streaked on the solidified agar surface. Test specimens of size $25 \mathrm{~mm}$ x 50 $\mathrm{mm}$ were pressed transversely across the five streaks to ensure the intimate contact with the agar surface. The plates were incubated at 37 $\pm 2{ }^{\circ} \mathrm{C}$ for 18 hours. The incubated plates were examined for interruptions of bacterial growth along the streaks of inoculum, beneath the specimen and beyond the fabric edge (Anonymous, 2013).

\section{Results and Discussion}

\section{Total Phenolic Content (TPC)}

Folin-Ciocalteu reagent, a mixture of phosphotungstic (H3 PW12O40) and phosphomolybdic (H3 PMo12O40) acids, is reduced to blue oxides of tungstene (W8 O23) and molybdene (Mo8 O23) during phenol oxidation. This reaction occurs under alkaline condition provided by sodium carbonate. The intensity of blue colour reflects the quantity of phenolic compounds, which can be measured using spectrophotometer.

Table 1 revealed that TPC concentration of $E$. globulus leaf was found to be high in ethanol $(302.67 \mathrm{mg} / \mathrm{g})$ extract followed by methanol $(276.53 \mathrm{mg} / \mathrm{g})$ and distilled water
$(197.94 \mathrm{mg} / \mathrm{g})$ extracts. On the other hand, aqueous extract $(465.82 \mathrm{mg} / \mathrm{g})$ of $T$. cordifolia yielded higher amount of TPC compared to methanol $(301.42 \mathrm{mg} / \mathrm{g})$ and ethanol $(264.06 \mathrm{mg} / \mathrm{g})$ extracts. Meanwhile, phenolic content was found to be high in ethanol extract (42.20mg/g) of $T$. procumbens followed by aqueous $(36.73 \mathrm{mg} / \mathrm{g})$ and methanol $(25.53 \mathrm{mg} / \mathrm{g})$ extracts.

Huda-Faujan et al., (2007) mentioned that the different levels of TPC may be attributed to different plants, procedures and standards used to express the TPCs; the colour measurement of Folin-Ciocalteu reagent and perhaps presence of other components that can react with Folin-Ciocalteu reagent.

\section{Antibacterial effect of plant extracts}

The result of antibacterial activity of plant extracts is summarized in Table 2 and Plate 1a $\& 1 b$, respectively. The leaf extract of all plant sources showed varying degrees of inhibition zones against both the test organisms at different concentrations.

It is apparent from the Table that among the plant extracts, the concentrated eucalyptus leaf extract showed maximum zone of inhibition against both Staphylococcus aureus (23mm) and Escherchia coli $(20 \mathrm{~mm})$ as compared to antibacterial activity of $18 \mathrm{~mm}$ against both test organisms at 10 per cent concentration. The antibacterial activity of tridax was present only in concentrated form against both $S$. aureus $(16 \mathrm{~mm})$ and E. coli $(15 \mathrm{~mm})$.

On the other hand, only concentrated extract of tinospora showed positive antibacterial activity against Staphylococcus aureus $(19 \mathrm{~mm})$ while negative results were observed for Escherchia coli at all the concentration levels. The results showed that increase in concentration of extract increased the zone of inhibition against the microorganisms. 
Table.1 TPC of the leaf extracts

\begin{tabular}{|l|c|c|c|}
\hline \multirow{2}{*}{ Extraction solvent } & \multicolumn{3}{|c|}{ Total phenolic content (GAE* mg/g) } \\
\cline { 2 - 4 } & E. globulus & T. cordifolia & T. procumbens \\
\hline Aqueous & $197.94 \pm 19.31$ & $465.82 \pm 23.04$ & $36.73 \pm 9.03$ \\
\hline Ethanol & $302.67 \pm 15.03$ & $264.06 \pm 18.41$ & $42.20 \pm 10.57$ \\
\hline Methanol & $276.53 \pm 10.45$ & $301.42 \pm 29.69$ & $25.53 \pm 12.45$ \\
\hline
\end{tabular}

*GAE: Gallic acid equivalent of fresh sample

All values are mean of triplicate experiments

Table.2 Antibacterial activity of plant extracts by Well diffusion method

\begin{tabular}{|c|c|c|c|c|}
\hline \multirow{2}{*}{$\begin{array}{l}\text { SI. } \\
\text { No. }\end{array}$} & \multirow[t]{2}{*}{ Source } & \multirow{2}{*}{$\begin{array}{c}\text { Concentration } \\
(\%)\end{array}$} & \multicolumn{2}{|c|}{ Zone of inhibition (mm) } \\
\hline & & & $\begin{array}{c}\text { Staphylococcus } \\
\text { aureus }\end{array}$ & $\begin{array}{c}\text { Escherchia } \\
\text { Coli }\end{array}$ \\
\hline \multirow[t]{3}{*}{1} & \multirow{3}{*}{$\begin{array}{l}\text { Eucalyptus } \\
\text { (Eucalyptus globulus) }\end{array}$} & 5 & NI & NI \\
\hline & & 10 & 18 & 18 \\
\hline & & 100 & 23 & 20 \\
\hline \multirow[t]{3}{*}{2} & \multirow{3}{*}{$\begin{array}{l}\text { Tinospora } \\
\text { (Tinospora cordifolia) }\end{array}$} & 5 & NI & NI \\
\hline & & 10 & NI & NI \\
\hline & & 100 & 19 & NI \\
\hline \multirow[t]{3}{*}{3} & \multirow{3}{*}{$\begin{array}{l}\text { Tridax } \\
\text { (Tridax procumbens) }\end{array}$} & 5 & NI & NI \\
\hline & & 10 & NI & NI \\
\hline & & 100 & 16 & 15 \\
\hline
\end{tabular}

NI: No zone of inhibition

Table.3 Antibacterial activity of treated fabrics

\begin{tabular}{|c|c|c|c|c|c|}
\hline \multirow{2}{*}{$\begin{array}{l}\text { Sl. } \\
\text { No. }\end{array}$} & \multirow[t]{2}{*}{ Particulars } & \multirow[t]{2}{*}{ Conc. } & \multirow[t]{2}{*}{ Test organisms } & \multicolumn{2}{|c|}{ Zone of inhibition } \\
\hline & & & & $\begin{array}{l}\text { Inhibition } \\
\text { zone (mm) }\end{array}$ & $\begin{array}{l}\text { Growth under } \\
\text { specimen }\end{array}$ \\
\hline \multirow[t]{4}{*}{1} & \multirow{4}{*}{$\begin{array}{l}\text { Eucalyptus } \\
\text { globulus }\end{array}$} & \multirow[t]{2}{*}{$5 \%$} & Staphylococcus aureus & No zone & No growth* \\
\hline & & & Escherchia coli & No zone & No growth* \\
\hline & & \multirow[t]{2}{*}{$10 \%$} & Staphylococcus aureus & No zone & No growth* \\
\hline & & & Escherchia coli & No zone & No growth* \\
\hline \multirow[t]{4}{*}{2} & \multirow{4}{*}{$\begin{array}{l}\text { Tinospora } \\
\text { cordifolia }\end{array}$} & \multirow[t]{2}{*}{$5 \%$} & Staphylococcus aureus & No zone & Growth \\
\hline & & & Escherchia coli & No zone & Growth \\
\hline & & \multirow{2}{*}{$10 \%$} & Staphylococcus aureus & No zone & No growth* \\
\hline & & & Escherchia coli & No zone & Growth \\
\hline \multirow[t]{4}{*}{3} & \multirow{4}{*}{$\begin{array}{l}\text { Tridax } \\
\text { procumbens }\end{array}$} & \multirow[t]{2}{*}{$5 \%$} & Staphylococcus aureus & No zone & Growth \\
\hline & & & Escherchia coli & No zone & Growth \\
\hline & & \multirow[t]{2}{*}{$10 \%$} & Staphylococcus aureus & No zone & No growth* \\
\hline & & & Escherchia coli & No zone & No growth * \\
\hline
\end{tabular}

* Antibacterial activity present 
Fig.1 Total phenolic content (TPC): Calibration curve

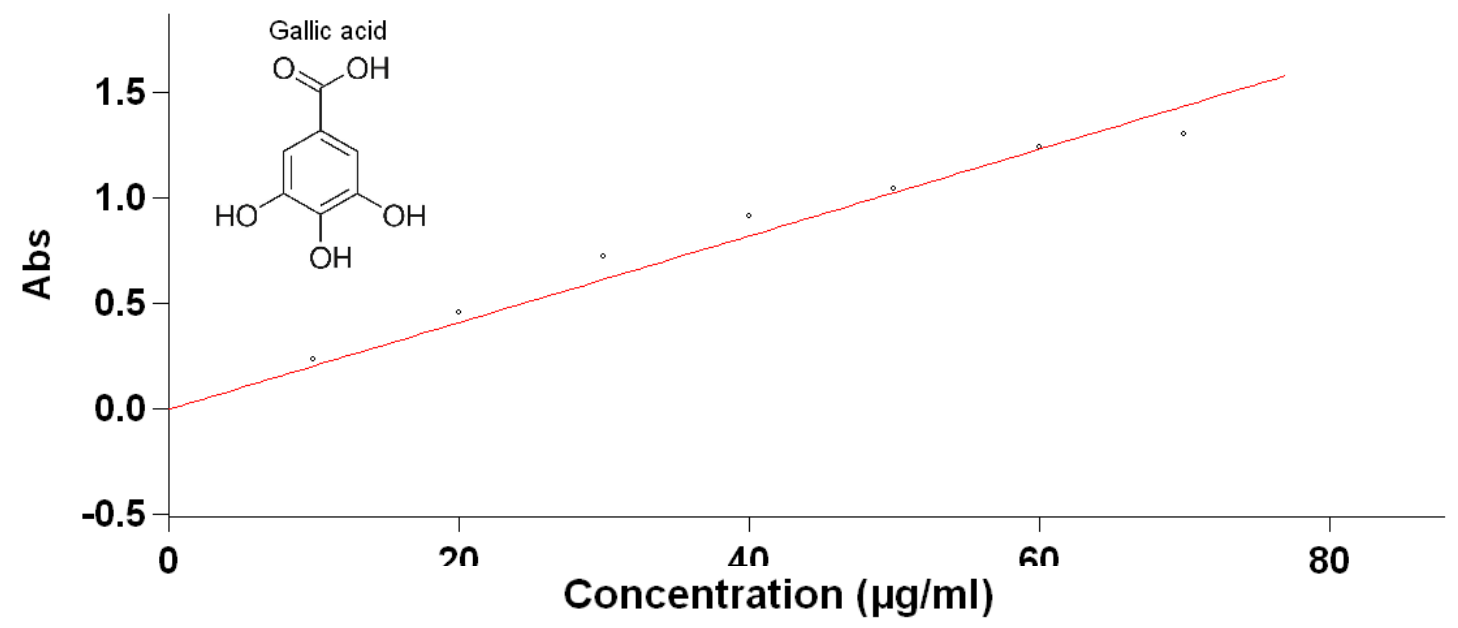

Plate.1a Antibacterial effect of plant extracts against S. aureus: (A) E. globulus, (B) T. cordifolia and (C) T. procumbens
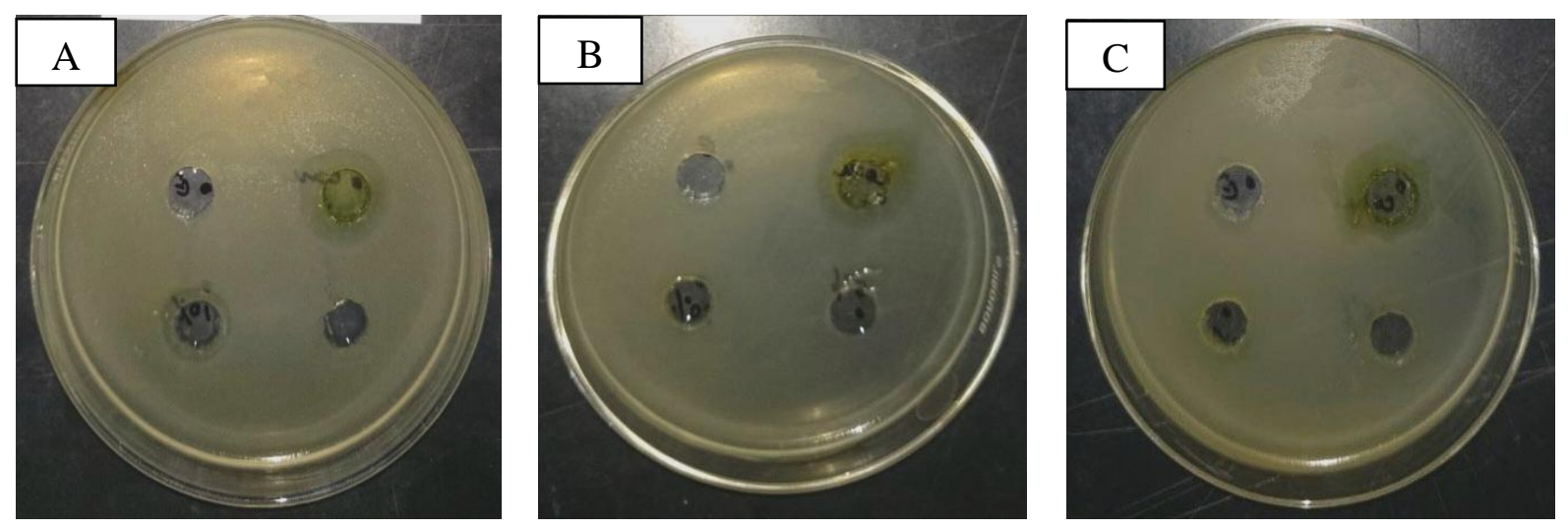

Plate.1b Antibacterial effect of plant extracts against E. coli: (A) E. globulus, (B) T. cordifolia and (C) T. procumbens
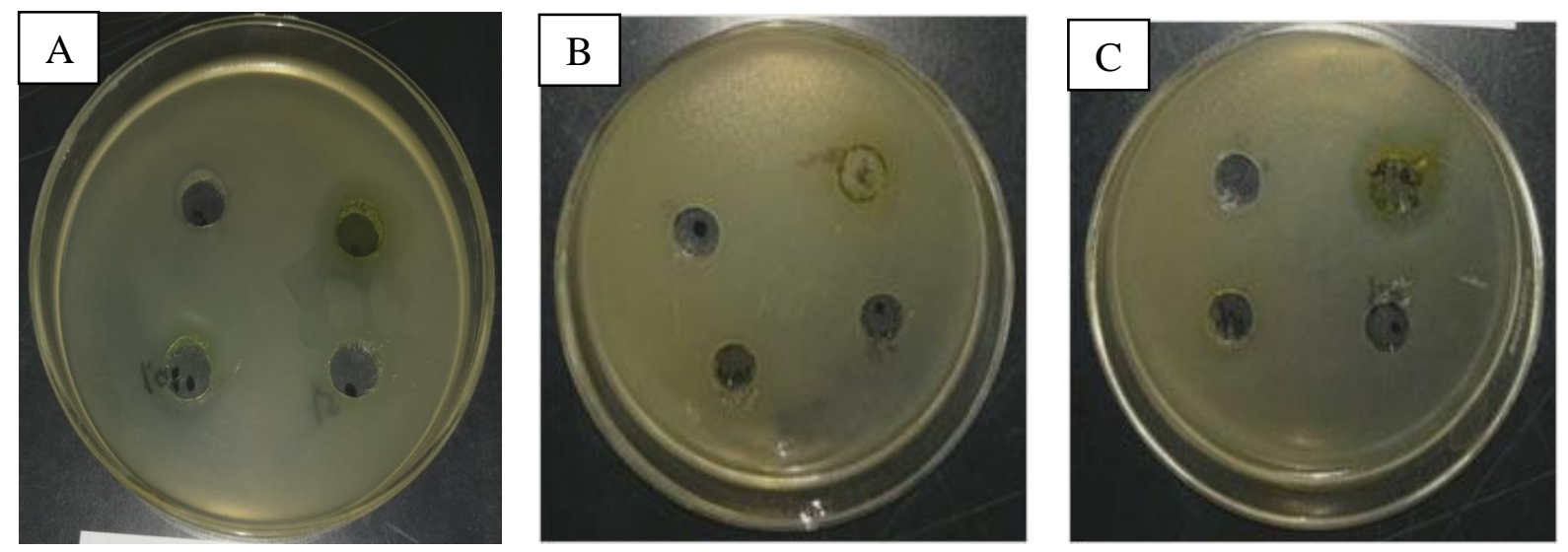
Plate.2a Antibacterial activity of treated fabrics against S. aureus: (A) E. globulus, (B) T. cordifolia and (C) T. procumbens
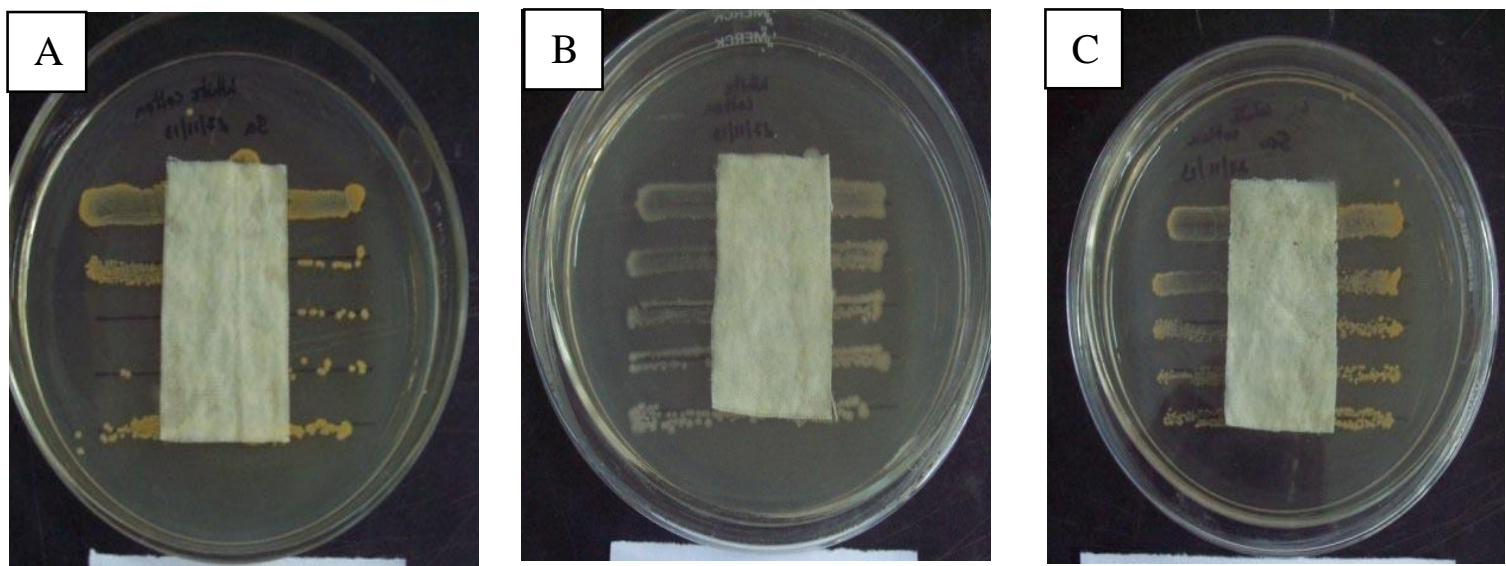

Plate.2b Antibacterial activity of treated fabrics against E. coli: (A) E. globulus, (B) T. cordifolia and (C) T. procumbens
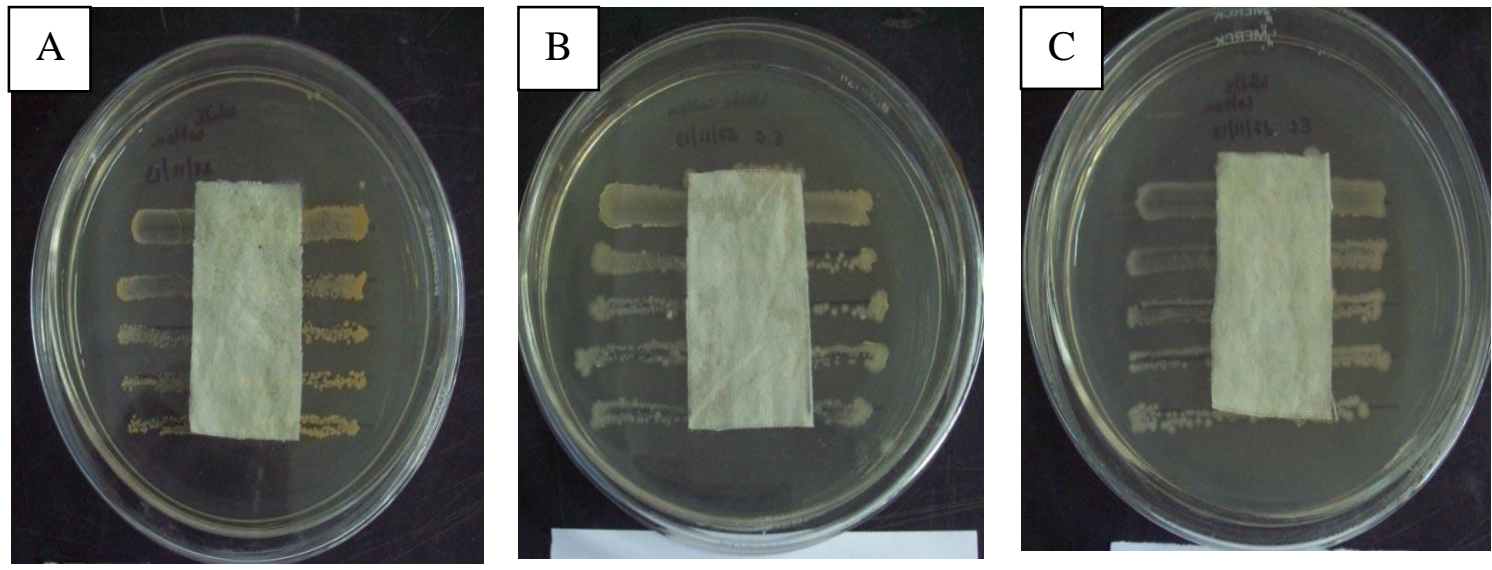

The variation in the antibacterial activity of the plant extracts can be attributed to inoculum size, type of media used, type of solvent used for extraction, extraction procedure, incubation time and temperature, part of the plant used and its time of collection, method of extraction procedure, incubation time and temperature, method of antibacterial assay and strain activity (Jahan et al., 2011). Meanwhile, among the bacterial species, comparatively higher inhibition zone was observed against Gram positive (Staphylococcus aureus) bacteria than Gram negative (Escherichia coli) bacteria.

\section{Antibacterial activity of treated fabric samples}

Antibacterial activity of fabric samples treated with 5 per cent and 10 per cent plant extracts against Staphylococcus aureus and Escherchia coli is depicted in Table 3 and Plate $2 \mathrm{a}$ and $2 \mathrm{~b}$. It is apparent from the Table that though none of the plant sources exhibited zone of inhibition but had better antibacterial activity against the selected test organisms. Antibacterial activity of tridax was found to be positive against both test organisms i.e. S. aureus and E. coli at 10 per 
cent concentration whereas 5 per cent extract exhibited negative antibacterial activity for both bacteria. Contrarily, eucalyptus showed significant antibacterial activity against $S$. aureus and $E$. coli at both concentration levels. However, antibacterial activity of tinospora was confined only to Gram positive ( $S$. aureus) bacterium at 10 per cent concentration.

Lack of zone of inhibition does not necessarily mean an absence of activity. A zone is generally shown by antimicrobial agents that are 'leaching type', i.e., they leach out of the fabric and kill the microbes present on as well as around the treated fabric. Generally, the bigger the zone, the higher is the antibacterial activity (Gupta and Laha, 2007).

The plant based antimicrobial agents have enormous therapeutic potential as they do not impose any side effects to the human beings. Further, it was observed that several plant extract could be effective against both Gram positive and Gram negative bacteria depending on the type of components present in the plant extract. Although all plant sources had antibacterial effect on $S$. aureus bacterium at different concentration, their effects changed against $E$. coli. Hence, it can be stated that the bacterial inhibition can vary with the plant sources, the solvent used for extraction, and the organism tested (Mahesh et al., 2011). This is particularly significant in the environment containing both the types of organism and highlighted the essentialities of the eco-friendly coating of natural plant extract on medical cloths.

Environment friendly natural products for textile application are gaining interest, worldwide. The relatively lower incidence of adverse reactions occurring from natural sources coupled with their reduced cost can be exploited as an attractive eco-friendly alternative to synthetic agents for textile wet processing. The results of present study clearly indicate that the antibacterial activity vary with the species of the plants and solvent used for extraction. Consequently, the antibacterial activity of plants tested can be explained with new studies by using different solvents for extraction, other bacteria and different parts of plants, accurately. Thus, the study ascertains the value of plants used in ayurveda, which could be of considerable interest to develop hygiene textiles and related goods.

\section{References}

Anonymous, 2013. Training program for testing antimicrobial textiles, The Synthetic and Art Silk Mills' Research Association (Sasmira).

Cho, J. Y., Nam, K. H., Kim, A. R., Park, J., Yoo, E. S., Baik, K. U., Yu, Y. H., Park, M. H., 2001. In vitro and in vivo immunomodulatory effects of syringin. J. Pharm. Pharmacol. 53(9):1287-1294.

Gupta, D. and Laha, A., 2007. Antimicrobial activity of cotton fabric treated with Quercus infectoria extract. Indian J. Fibre Tex. Res., 32(1): 88-92.

Hooda, S., Khambra, K., Yadav, N. and Sikka, V. K., 2013. Effect of laundering on herbal finish of cotton. International Journal of Textile and Fashion Technology, 3(4): 35-42.

Huda-Faujan, N., Noriham, A., Norrakiah, A. S. and Babji, A. S., 2007. Antioxidative activities of water extracts of some Malaysian herbs. Asian Food Journal, 14(1): 61-68.

Jahan, F., Lawrence, R., Kumar, V. and Junaid, M., 2011. Evaluation of antimicrobial activity of plant extracts on antibiotic susceptible and resistant Staphylococcus aureus strains. J. Chem. Pharm. Res., 3(4): 777-789.

Kale, S. S. and Deshmukh, A. S., 2014. 
Tridax procumbens: A medicinal gift of nature. Asian Journal of Research in Biological and Pharmaceutical Sciences, 2(4): 159-162.

Khurshid, M. F., Ayyoob, M., Asad, M. and Shah, S. N. H., 2015. Assessment of eco-friendly natural antimicrobial textile finish extracted from aloe vera and neem plants. Fibres and Textiles in Eastern Europe, 23, 6(114): 120-123.

Mahesh, S., Reddy, A. H. M. and Kumar, V. G., 2011. Studies on antimicrobial textile finish using certain plant natural products. Proceedings of International Conference on Advances in Biotechnology and Pharmaceutical Sciences, Bangkok, pp 253-258.

Sathianarayanan, M. P., Chaudhari, B. M. and Bhat, N. V., 2011. Development of durable antibacterial agent from banajwaiin seed (Thymus serpyllum) for cotton fabric. Indian J. Fibre Tex. Res., 36(3): 234-241.

Singleton, V. L. and Rossi, J. A., 1965. Colorimetry of total phenolics with phosphomolybdic-phosphotungstic acid reagents. Am. J. Enol. Vitic. 16: 144158.

Vastrad, J. V., Goudar, G. and Byadgi, S. A., 2016. Characterization of phenolic compounds in Eucalyptus globulus and Cymbopogan citratus leaf extracts. The Bioscan, 11(4): 2153-2156.

Vastrad, J. V., Goudar, G., Byadgi, S. A., Devi, R. D. and Kotur, R., 2015. Identification of bio-active components in leaf extracts of Aloe vera, Ocimum tenuiflorum (Tulasi) and Tinospora cordifolia (Amrutballi). Journal of Medicinal Plants Research, 9(28): 764770 .

\section{How to cite this article:}

Jyoti V. Vastrad and Shameembanu A. Byadgi. 2018. Eco-friendly Antimicrobial Finishing of Cotton Fabric using Plant Extracts. Int.J.Curr.Microbiol.App.Sci. 7(02): 284-292. doi: https://doi.org/10.20546/ijcmas.2018.702.037 